\title{
The application of Chinese ink painting in the modern clothing
}

\author{
Shuli Wen ${ }^{1, a}$ \\ ${ }^{1}$ Jiangxi Institute of Fashion Technology, Jiangxi, Nanchang, 330201 \\ a377738947@qq.com
}

Keywords: Ink painting; Chinese elements; Clothing design

\begin{abstract}
In pluralism, the era of globalization, clothing has become an international fashion with Chinese elements should not be neglected scenery, how to use ink painting in the dress designing, make the Chinese culture can lead the world, become a problem now in urgent need of research. Chinese ink painting is the expression of the Chinese nation's unique aesthetic form, is an important part of traditional culture, it has various forms and methods and have very strong adornment sex and artistic expression. Derived from ink painting essence element, reasonable application in modern clothing design, can show a Chinese ink and lasting appeal. Article through to the ink painting, deeply understand that the Chinese ink painting elements into the modern clothing, can not only cater to the modern people to the requirement of clothing is beautiful and the function, increase the cultural implications of the clothing, China's market competitiveness, at the same time also can give the traditional culture and art new forms and carriers.
\end{abstract}

\section{The development of Chinese ink painting of modern clothing at home}

From after the reform and opening up to the present, Chinese clothing westernization of the wind has been more and more serious, is the international standard of chanting, based on the fine tradition of Chinese clothing disappeared, people Shouting "to protect the Chinese traditional costume culture", followed by a constant exploration and innovation of Chinese clothing designers. Combine traditional elements and clothing and fashion with the traditional coexist in our daily life has become a new topic, more and more designers to find the answer in the elements of Chinese ink painting and comprehension.

In the 20th century Chinese art characteristics and any after a century, the same artists in this era met many problems, such as art, and the relationship of The Times, art and politics, the relationship between art and economy, the relationship between art and mass, the relationship between art and behavior, the relationship between art and creation of relationship, and so on, but there is such a contradiction, is the contradiction between tradition and innovation, is also a core issue of modern artists explore, how to select the essence, remove the dross, innovation. Clothing shows the values and spirit of a person also showed an era, a country folk customs, history and culture. In China international fashion week 2011 chun xia series published Chinese designer BoTao will traditional Chinese ink painting and calligraphy into fashion design concept, fully embodies the ink painting artistically clever and elegant, create a picturesque, beautiful artistic conception, meaning long finish.

\section{The application of Chinese ink painting in the modern clothing}

Chinese ink and wash color design element with the modern clothing. In fashion design, colour is to stimulate people to the first element of vision, is can't or lack of clothing style of a factor, has a unique role. Modern clothing color change by futurism people of aesthetic idea, also gradually become blurred, abstract and mixed and disorderly. Especially the social rapid pace of life, let people pay more attention to the pursuit of the spirit, because different colorific hue, lightness and purity have different characteristics, the properties of the gray is a kind of another gorgeous colour, show clear or depression, or elegant, or amiable colour character. Chinese ink color performance in black, white and grey color light strong, through the change of the multilayer, through a variety of different gray overlay, density, space, etc., presents the color between the harmonious beauty of wireless, through the change of the colors, brush strokes make picture more beautiful, elegant, of 
which the calligraphy of saturated, detail drawing skills, make the picture has both the beauty of artistic conception, aka also has the beauty of craftsmanship in the details. The traditional Chinese color ink points five colours, pay attention to the harmonious and lasting appeal. Clothing design can also find in black, white, grey ink and the phase compatibility of lasting appeal, of black and white ash three levels of processing and dynamic effects of incisively and vividly to make clothing unique charm.

Chinese ink painting element and the application of modern clothing fabrics. The characteristics of ink painting is affected by the performance of the tools and materials. Traditional paintings usually use silk painting and rice paper, the characteristics of the tools and materials in the use of the painter can play to the extreme. The weight of the permeability of the Chinese rice paper, brush pen, points of conjured out of limitless possibilities, make the language of the state of Chinese painting is not words but meanings. To a large extent, is a traditional Chinese painting tools, materials, made today's achievements of Chinese painting. These tools, and becomes one of their master, not only constitute a beautiful picture scroll, and composition of the picture of each stroke with unique artistic beauty, at the same time, in the service of art as a whole. Each ink painting, painting under different humidity of the air, the strength of different writing, will create a different artistic effect, only a person familiar with the material, the skills to master tool.

Is one of the three elements of clothing fabric material, and also reflects the life of the carrier, is the foundation of the clothing creation. And fabric options as ink material effect, in the different selection of clothing will show the atmosphere straightforward or lightness feminine. For the fabric to create is not only to the design of a single material, and increase the one of garments' integral value and the practice of art appreciation, but also often can be changed decayed for magical. As the traditional ink painting will dot, line, face gimmick comprehensive use and sui generis, these, the modification of clothing accessories to make new fabric to produce rich and mysterious change. The design of fabric reconstruction has a unique role, namely present fabric texture itself, and become part of intention. In modern clothing art performance, for the fabric to create more and more emphasized, because of the added value of it, is more and more, the joining together of fabrics, forcible entry, restructuring and hollow out like ink, multi-level space to the person. Material creation itself is a reflection of the artistic creation.

The overall combination of elements of Chinese ink painting and modern clothing. Modern clothing design, for the application of traditional ink painting reflects the more and more application of organic combination with the creation of the new material, there are more, rich artistic elements. Different texture, color, weight of material restructuring together, formed a strong visual impact. Will the combination of clothing and ink painting not only confined to the design of application, but from the clothing modelling, the structure to the process of comprehensive survey, opened up a new design idea. The ultimate representation of the traditional ink painting is almost entirely a two-dimensional plane, but now is converted to dress a 3 dimensional these things, and carrier of the people, reflects the vitality of three-dimensional, is a kind of extension of dimensions, as well as transformation of the artistic form, also make the combination of Chinese and western aesthetics and harmony. To modern ink and wash clothes the wind of of primitive simplicity at the same time, also bring strong Oriental philosophy to the fashion industry under the influence of fashion ideas. Enable people to have a brand new senses and the embodiment of the new, let people feel the profound Oriental culture, and the concept of a balance of Yin and Yang. 4 Chinese ink painting element in modern clothing in the future development trend

At the beginning of the 20th century, western clothing was introduced into China, after a century since the unprecedented huge impact, occupy the market of China, and compete with Chinese style clothing. Due to the international clothing fashion trend in recent years more strongly into the main style, guide and influence Chinese consumers. Chinese style clothing, therefore, must want to develop the combination of fashion, with the style of the fashion variety arouse people love for fashion, driven by the designer in the inheritance and absorption of traditional culture at the same time, promote our country modern clothing design, is the trend of The Times.

The first thing to do, it is certainly constant change and development of Chinese style costume 
is useful. This shows that originally belong to national is heading for the world, only to the international. Also known and accepted by the international and the world, many designers learn design elements from traditional Chinese culture, including ink element is the designer in love, at the same time, the designer to add their own concept of bold, make a design on the clothes in the style of innovation, for the national traditional art elements into new life. Promoting the development of modern costume design in China, and second, we should to seek common ground while putting aside differences attitude to treat the change of Chinese clothing, while we try to overcome the sense of conformism, in addition we should alert the plot of the foreigners, more not easy, thoughtless to its improvement, also don't blindly cater to the European and American design style, and to innovate in the inheritance, the good and discard the dregs, on the world clothing stage show its glamour.

\section{Conclusion}

In the contemporary, to dominate the world popular agitation restoring ancient ways, Chinese ink painting elements also become a source of inspiration of some designers at home and abroad, but also aroused designer identification of the national style. They began to improve Chinese traditional costume elements, but also increased the study of native culture, and fully integrated into the modern design concept, ensure China fashion vibrant finally. In the way of the development of modern clothing, a large number of designers to create works of different styles to reflect their understanding of their original ideas and traditional garb. These works virtually become the focus of attention in our life. Category in modern people's aesthetic idea and dress style as foothold, to join the traditional art ably, to go beyond the framework of traditional culture, realize the perfect interaction of modern and traditional. Show another kind of person is match well of Chinese and western, make public individual character, experience new shock effect, another is a modern design thinking into the traditional costume, looking for restoring ancient ways the best combining site and avant-garde. These three kinds of costume design thinking is affects the development of modern costume design in our country. Of China's garment industry has injected new vitality, fashion life growth.

\section{Reference}

[1] shine. Contemporary ink painting language expression [J]. Journal of adornment, 2003, (9).

Theory of [2] wenjun li. The beauty of the black and white of the ink painting [J]. Journal of art and design, 2002, (2).

[3] skin firm. A new era under the background of globalization of ink painting [J]. Journal of art, 2003, (11).

[4] zu-fang zhang. Chinese and western costume [M]. Shanghai people's publishing house, 2002. (51-67).

[5] Curtis. Chinese ink painting: origin. Aesthetic. Performance [M]. Yunnan university press, 2006, (12).

When over time - [6] xiao-mei zhou. Ink ink exploration and thinking [J]. Journal of huaibei vocational technical college school, 2007 (6).

[7] Bai Tianyou. The application of Chinese traditional elements in the clothing design [J]. Journal of Yangtze university, 2009 (8). 